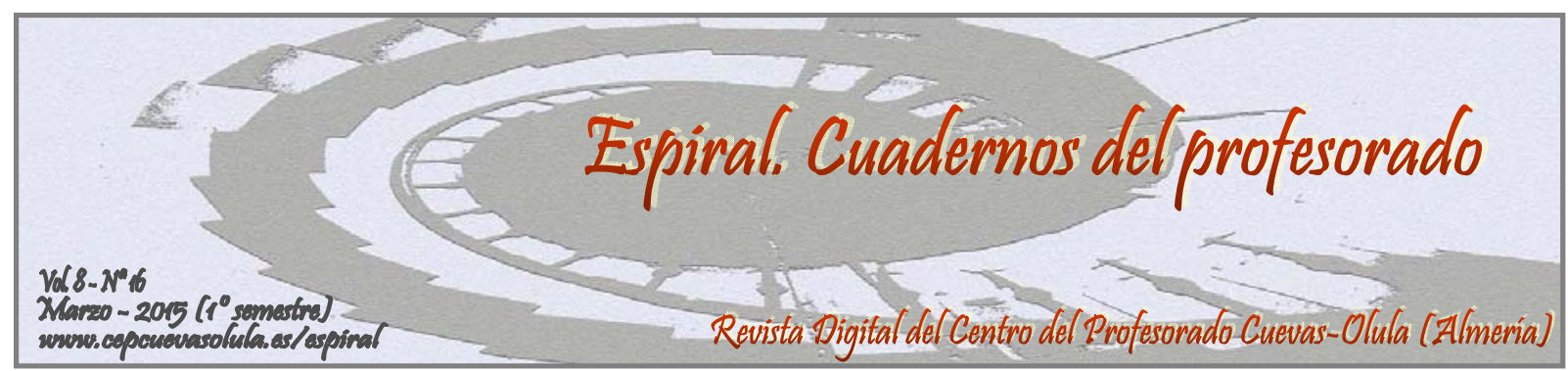

\title{
EDUCACIÓN MULTIDISCIPLINAR: RALLY FOTOGRÁFICO EN EL MEDIO NATURAL
}

\author{
MULTIDISCIPLINARY EDUCATION: PHOTOGRAPHIC RALLY IN THE \\ NATURAL ENVIRONMENT
}

\author{
Fátima Martín Acosta
}

Facultad de Ciencias del Deporte, Universidad de Murcia, España

RESUMEN: Cada vez es más conocido lo atractivas que son las actividades en el Medio Natural, en general y en la escuela, en particular, por lo tanto llevarnos parte de la educación fuera del aula puede ser algo muy positivo. Teniendo como objetivo convertir la educación en algo atractivo y conseguir que los conocimientos se obtengan mediante la vivencia y así hacerlos más significativos, vemos conveniente el uso del Rally Fotográfico como una herramienta de enseñanza. Esta actividad nos puede proporcionar grandes y diversas posibilidades para abordar distintos objetivos. El enfoque y las características que le demos lo harán adecuado a un grupo u otro, pudiendo ser escolares $\mathrm{o}$ adultos. Esta actividad nos facilita un trabajo multidisciplinar e interdisciplinar en el que integremos varias materias. El conocimiento del entorno urbano, como el natural proporcionan un desarrollo más integral del alumno. Proponemos una serie de pasos para su elaboración y diferentes ejemplos.

Palabras clave: interdisciplinariedad, medio natural, fotografía, cultura.

ABSTRACT: It is increasingly known how attractive activities in the Natural Environment are in general and school in particular, therefore to lead part of education outside the classroom can be very positive. Aiming to make the learning attractive and ensure that knowledge obtained through the experience and make them more meaningful, we find convenient to use the Photographic Rally as a teaching tool. This activity can provide us great possibilities to address different objectives. The approach and the features that will give you the right to one group or another and may be school children or adults. This activity gives us a multidisciplinary and interdisciplinary work that integrates several subjects. Knowledge of the urban environment, such as natural provides a more holistic development of students. We propose a series of steps for processing and various examples.

Key words: interdisciplinarity, environment, photography, culture.

Martín Acosta, F. (2015). Educación multidisciplinar: rally fotográfico en el medio natural.

Espiral. Cuadernos del Profesorado, 8(16), 42-49. Disponible en:

http://www.cepcuevasolula.es/espiral

Fecha de recepción: 12/09/2014

Fecha de aceptación: 17/12/2014

Enviar correspondencia a: fatima_m.18@hotmail.com 


\section{1.- INTRODUCCIÓN}

El Rally Fotográfico consiste en realizar un recorrido por un entorno natural o urbano con la ayuda de un mapa, incluso una brújula puede ser necesaria, en el que vienen destacados una serie de lugares a visitar. Cada uno de estos espacios tiene asociada la foto de un objeto o lugar representativo de la zona a conocer y una pregunta relacionada.

En esta actividad se integran otras como el senderismo, la orientación y la Gymkhana, lo que le da gran variedad de posibilidades. Además, se puede enfocar para conocer la fauna, flora y zonas de interés del lugar, para trabajar la educación ambiental, centrarlo en conseguir buenas fotografías del paisaje, para realizar actividades transversales en escolares, etc.

Indudablemente, el Rally Fotográfico favorece la realización de ejercicio de una forma tan saludable como lo es hacerlo al aire libre, relacionándonos directamente con el Medio Natural. Esto nos permite un conocimiento empírico del mismo y un desarrollo más integral del participante. Contribuirá al uso del tiempo libre y ocio en actividades sanas, que además nos hagan conocer mejor nuestro propio entorno y sus posibilidades.

Igualmente, fomenta el trabajo en valores como la cooperación, respeto, solidaridad, responsabilidad, compromiso, etc. Asimismo, puede ir dirigido y participar personas de cualquier edad, solo habrá que adaptarlo. Si es para escolares lo basaremos en el curriculum y el recorrido tendrá la dificultad adecuada a la edad, para personas más adultas se puede complicar el recorrido y la duración, para familias se hará que todos se puedan sentir útiles, etc.

Por otro lado, a la hora de programar la actividad tenemos la posibilidad de orientar la actividad con gran diversidad de temáticas y fines según nuestro interés y el de las personas a las que va dirigido. No podemos olvidar que favoreceremos el uso y lectura de mapas y desarrollo de la orientación, lo que puede ser muy útil en el día a día.

Por último, la importancia que se le ha da la fotografía en sí favorece la creatividad y el lado artístico de los participantes. Sin olvidar el atractivo y popularidad que tiene la fotografía en la actualidad.

\section{RALLY FOTOGRÁFICO EN LA EDUCACIÓN}

Con la realización de un Rally Fotográfico en la escuela podemos abordar gran variedad de contenidos de Educación Física, Ciencias Sociales, Geografía e Historia y Ciencias de la Naturaleza, principalmente, pero podríamos relacionarlo con cualquier otro. Permitirá un trabajo multidisciplinar e interdisciplinar. Apoyándonos en el Real Decreto 1631/2006, de 29 de diciembre, por el que se establecen las enseñanzas mínimas correspondientes a la Educación Secundaria Obligatoria, observamos los contenidos que cumplen.

Ciencias de la Naturaleza:

Primer curso:

Educación Secundaría: Bloque 2.

- Utilización de técnicas de orientación. Observación del cielo diurno y nocturno.

- La Tierra en el Universo y Bloque 4. Los seres vivos y su diversidad.

- Características de los seres vivos.

Segundo curso:

Bloque 6. El medio ambiente natural.

- Biosfera, ecosfera y ecosistema. Identificación de los componentes de un ecosistema.

- Ecosistemas terrestres: los biomas. 
- Realización de indagaciones sencillas sobre algún ecosistema del entorno.

Tercer curso:

Bloque 6. Las personas y el medio ambiente.

- La actividad humana y el medio ambiente: Los recursos naturales y sus tipos.

- Consecuencias ambientales del consumo humano de energía.

- Valoración del impacto de la actividad humana en los ecosistemas.

- Principales problemas ambientales de la actualidad.

- Valoración de la necesidad de cuidar del medio ambiente y adoptar conductas solidarias y respetuosas con él.

\section{Ciencias Sociales, Geografía e Historia:}

Educación Secundaría: Bloque 2. La Tierra y los medios naturales.

Primer curso:

- Aplicación de técnicas de orientación y localización geográfica.

- Caracterización de los principales medios naturales, identificando los componentes básicos del relieve, los climas, las aguas y la vegetación; comprensión de las interacciones que mantienen.

- Observación e interpretación de imágenes representativas de los mismos.

- Valoración de la diversidad como riqueza que hay que conservar.

- Estudio de algún problema medioambiental como, por ejemplo, la acción humana sobre la vegetación, el problema del agua o el cambio climático.

- Toma de conciencia de las posibilidades que el medio ofrece y disposición favorable para contribuir al mantenimiento de la biodiversidad y a un desarrollo sostenible.

\section{Educación Física:}

Educación Secundaria; Bloque 4. Actividades en el medio natural.

Primer curso:

- Las actividades físico-deportivas en el medio natural.

- Realización de recorridos a partir de la identificación de señales de rastreo.

- Aceptación y respeto de las normas para la conservación del medio urbano y natural.

Segundo curso:

- El senderismo: descripción, tipos de sendero, material y vestimenta necesaria.

- Realización de recorridos preferentemente en el medio natural.

- Toma de conciencia de los usos adecuados del medio urbano y natural.

- Respeto del medio ambiente y valoración del mismo como lugar rico en recursos para la realización de actividades recreativas.

Tercer curso: 
- Normas de seguridad para la realización de recorridos de orientación en el medio urbano y natural.

- Realización de recorridos de orientación, a partir del uso de elementos básicos de orientación natural y de la utilización de mapas.

- Aceptación de las normas de seguridad y protección en la realización de actividades de orientación

- Relación entre la actividad física, la salud y el medio natural.

- Participación en la organización de actividades en el medio natural de bajo impacto ambiental, en el medio terrestre o acuático.

- Realización de las actividades organizadas en el medio natural. Toma de conciencia del impacto que tienen algunas actividades físicodeportivas en el medio natural.

Además, da la posibilidad de trabajar las Competencias Básicas (Real Decreto 1631/2006, de 29 de diciembre).

\section{Competencia en comunicación lingüística}

Como en toda actividad grupal es imprescindible la comunicación, conversar, está abierta a expresar cualquier opinión y, por supuesto, a escuchar a los demás. Leer y escribir también forma parte de la actividad, comprender las pistas, las preguntas, responder con coherencia, etc.

\section{Competencia matemática}

El uso de la competencia matemática está presente cuando se hace uso de rumbos y distancias para orientarse. Además, puede ser directamente la temática y durante el recorrido se pedirán fotos de figuras geometrías en la naturaleza, mediciones, etc.

\section{Competencia en el conocimiento y la interacción con el mundo físico}

Las actividades de este tipo ponen a prueba la habilidad para interaccionar con el mundo físico teniéndonos que adaptar a las distintas situaciones en las que nos encontremos y poder trasladar después estas experiencias a la vida cotidiana. De esta forma nos permitiría incorporar la aplicación de conocimientos adquiridos anteriormente.

\section{Tratamiento de la información y competencia digital}

La información que se ofrece en esta actividad se transformará en conocimientos en el momento en el que tengan que trabajar y razonar con ella para poder seguir avanzando.

Las tecnologías de la información también se pueden integrar adaptando la actividad.

\section{Competencia social y ciudadana}

Esta actividad favorece la comprensión de la realidad histórica y social, su evolución, de la zona donde se realiza y se puede trasladar a otros contextos. Ayuda a valorar a los demás y a uno mismo y da facilidades para aprender a participar activamente en el día a día favoreciendo a la convivencia.

\section{Competencia cultural y artística}

Como otras competencias, los aspectos culturales o artísticos pueden ser la temática del Rally. El recorrido puede hacer que se visiten construcciones históricas, patrimonios culturales, lugares de ocio y turismo, etc.

La necesidad de realizar buenas fotos hace también que se trabaje la creatividad.

\section{Competencia para aprender a aprender}

Constantemente estarán poniendo a prueba su conocimiento y decidiendo estratégicamente cómo hacer uso de él y cómo manejar los recursos.

\section{Autonomía e iniciativa personal}

Esta actividad permite transformar las propias ideas en acciones, resolver problemas, tanto individuales como colectivos y ser consciente de los riesgos que se asumen y aprender de los errores. 
En definitiva, el Rally Fotográfico puede ser un medio atractivo con el que conocer una zona, ya sea de un pueblo o de un entorno natural y facilitar el conocimiento de los mismos. Por un lado, a quien venga de fuera les hará más fácil y divertido conocer lo más representativo de un lugar y por otro lado, quienes viven cerca ampliarán sus conocimientos además de valorar más su entorno. Esto puede hacer que se sea más responsable y respetuoso con el medio. Centrándonos ahora en los beneficios que nos aporta en el ámbito educativo, comparte lo citado anteriormente y también da la posibilidad de implicar otras asignaturas además de desarrollar y poner a prueba las distintas competencias haciendo un aprendizaje más significo para el alumnado. Es una actividad dinámica que se aleja del sedentarismo y la monotonía, favoreciendo la futura iniciativa de seguir conociendo el entorno y con esto ocupar el tiempo libre con actividades saludables.

\section{PROPUESTA PRÁCTICA}

Para la elaboración de un Rally Fotográfico es aconsejable tener en cuenta una serie de pasos para así partir con una buena planificación de la actividad y que se desarrolle correctamente. (Caballero, 2009; Contreras, Contreras y Román, 2005)

1. Determinar el espacio.

Concretar en qué espacio se va a realizar. Generalmente, las opciones son espacio urbano o medio natural y de ahí elegir la zona más concreta según la dificultad que queramos.

2. Tener en cuenta las edades de los participantes.

Determinar las edades de los participantes para adaptarlo a sus características ya que pueden participar niños y niñas, jóvenes, adultos o familias con diversas edades.

3. Recopilar mapas e información de la zona.

Los mapas se pueden obtener en los ayuntamientos de las localidades, en las diputaciones provinciales o mediante Google Earth o similares. La recopilación de información de la zona ayudará a elegir lo que queramos que conozcan los participantes y, por tanto, el hilo conductor de la actividad.

4. Seleccionar el hilo conductor de Rally fotográfico

La temática puede ser muy diversa y siempre está abierta a los intereses con los que se hace. Los más destacados serian; monumentos e historia, zonas e instalaciones relevantes, educación ambiental, plantas, etc.

5. Selección de puntos de interés.

El hilo conductor condicionará el recorrido y tiene que permitir conseguir los objetivos propuestos para ello tenemos que informarnos de su historia, características y demás. En este momento, también se deben sacar las fotos que servirán de orientación.

Se considerará el tráfico de la zona, el desnivel, la longitud del recorrido, permisos si fueran necesarios, dificultad del terreno, lugares de posible descanso, etc.

6. Elaboración de preguntas.

En cada punto de interés se encontrará una ficha en la que hay una pregunta, esta servirá para que obtengan más conocimientos y además ayude a conocer el nivel de implicación. Para su elaboración es importante considerar la población a la que va dirigido.

7. Seleccionar el premio para los ganadores y/o participantes.

Al final de la actividad se recogerán las fichas con las respuestas a las preguntas y las fotos de cada grupo. Se puede valorar si son correctas y la originalidad, así como el tiempo que tardaron en hacerlo.

Los premios pueden ser desde dinero, si hubo un precio de inscripción, a algún objeto significativo. Regalar un diploma por haber participado a todos puede ser una opción.

A continuación presentamos dos ejemplos de actividades.

Rally fotográfico urbano Mecina Bombarón 
La finalidad principal de esta actividad es hacer que los lugares en los que hay muchos pueblos cercanos los alumnos de los colegios, también podría ser para los habitantes en general, puedan conocer los otros pueblos de una forma más amena y divertida. Cada profesor planificaría la de su pueblo y se la daría a los otros profesores, incluso pueden ayudar los alumnos en su realización, ya que sabrán que es interesante conocer en su pueblo. Puede ser positivo además para fomentar el turismo de la propia zona.

La actividad va dirigida a un grupo de 24 niños y niñas de tercer curso, cuantos mayores sean trabajaran con mayor autonomía. Los subgrupos serían seis de cuatro personas. Tres profesores-as estarían situados en los lugares donde mayor dificultad o tráfico podría haber.

Se valorará el tiempo que se ha tardado en finalizar, la correcta respuesta a las preguntas y la originalidad de las fotos.

La distancia a recorrer es de 2, $2 \mathrm{Km}$ y la duración de 60 minutos aproximadamente.

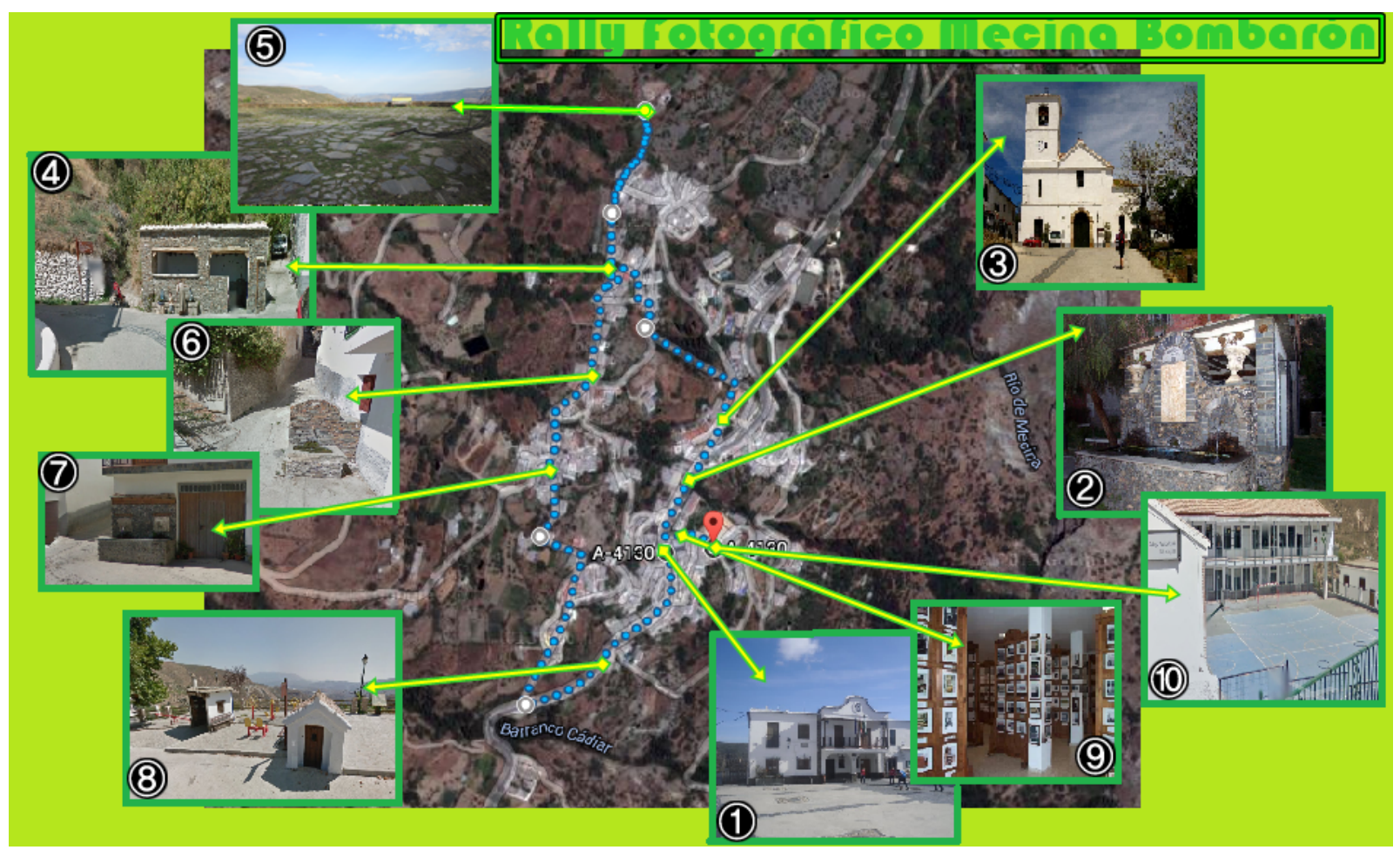

Figura 1: Mapa que llevan los participantes.

1. Ayuntamiento (Plaza Nueva, 1): Como sabemos, hidratarse es muy importante. Buscad un sitio donde beber agua que empieza la aventura.

Pregunta: ¿A cuántos pueblos pertenece este ayuntamiento? (Respuesta: Dos Mecina Bombarón y su pedanía Golco y a Yegen y su pedanía Montenegro)

2. Fuente San Miguel (Avenida José Antonio): ¿Cómo se llama esta fuente? Si lo sabes, solo tienes que encontrar donde vive este santo para llegar a la siguiente pista.

Pregunta: ¿De dónde procede el agua de esta fuente? (Respuesta: de un nacimiento de unos 100 metros más arriba)

3. Iglesia San Miguel (Calle Altilla): De la Calle Altilla al Barrio Alto...subid por una cuesta llena de castaños y seguid por las pequeñas calles que el sonido del agua os llevará hasta el siguiente lugar.

Pregunta: ¿Cuándo se celebran las fiestas patronales? (Respuesta: 28,29 y 30 de septiembre) 
4. Lavadero del Capitán (Calle Umbría): Bebed agua que ahora hay que subir una cuesta...nos saldremos un poco del pueblo para llegar a una era. ¡Mirad bien las señales!

Pregunta: ¿Qué ruta sendero comienza aquí? (Respuesta: La Acequia Alta)

5. Era el chorro (Calle Era del Chorro): Volved por donde habéis venido y la siguiente calle os dará el nombre de la fuente que tenéis que encontrar. Pista es el nombre de un árbol frutal.

Pregunta: ¿De qué cultivo, con el que la mayoría de vecinos del pueblo vive, nos encontramos rodeada la era? (Respuesta: habichuelas)

6. Fuente Manzano (Calle Manzano, $\mathrm{n}^{\circ} 10$ ): De fuente en fuente y sigo porque me lleva la corriente...continuad por la Calle Plaza Vieja que os llevará hasta la plaza con el mismo nombre.

Pregunta: ¿Qué es el edificio que hay en el cruce de camino? (Respuesta: el antiguo cuartel de la Guardia Civil)

7. Fuente Plaza Vieja (Calle Plaza vieja): Ahora toca bajar, llegad hasta la carretera y encontrareis el siguiente lugar. pueblo)

Pregunta: ¿Hacia dónde nos lleva la calle de “La Sierra”? (Respuesta: Hacia la sierra del

8. Ermita de las Ánimas (Carretera principal): Bajo la plaza del ayuntamiento encontrar un lugar que guarda en imágenes muchos recuerdos de este pueblo.

Pregunta: ¿Cómo se llama la otra ermita que hay en el pueblo? (Respuesta: Ermita de los Remedios)

9. Museo fotográfico (Calle Iglesia Vieja): No podemos irnos sin visitar donde más aprenden los niños y niñas de este pueblo

Pregunta: Tras ver las antiguas fotos ¿qué os ha llamado más la atención de los cambios en la forma de vida que muestran las imágenes con la actualidad? (Respuesta: Vestimenta, calles, matanzas, materiales de campo, etc.)

10. Colegio “Las Acequias” (Calle Iglesia Vieja): ¡Buen trabajo equipo!

Pregunta: ¿A dónde llevaríais en este pueblo a vuestra familia y amigos?

Rally Fotográfico Medio Natural

Esta actividad estaría dirigida para alumnos de segundo de secundaria. Para una clase de veinticuatro, se harán seis grupos de cuatro personas. La distancia es de 2,5 km y la duración de una hora y media, aproximadamente. Habrá profesores cada cierta distancia y siempre cerca de las zonas que pueden tener mayor dificultad.

La ruta de senderismo ya existente y está marcada en la localidad de Mecina Bombarón (Granada). El sendero sale del pueblo, el principio es por un camino de tierra y después sigue el recorrido de una de las antiquísimas acequias que riega las zonas de cultivo del pueblo. El desnivel es muy suave, y según la valoración MIDE vemos que cumple los siguientes valores:

Será una actividad en la que a través de la naturaleza y la actividad física se trabajan contenidos de distintas materias a través de retos que tendrán que conseguir fotografiar.

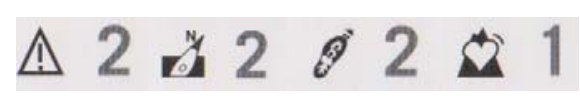

Figura 2. Valoración del sendero “Acequia Alta” según normas MIDE.

Una vez recopiladas las imágenes pueden servir como material en el aula para seguir trabajando los tipos de paisajes, relieves, fauna, flora, así como los diferentes contenidos que hemos utilizado.

Las fotos a conseguir en los lugares señalados son: 
1. ¡Mostrad en una foto el gran equipo que hacéis!

2. ¿Podremos encontrar en la naturaleza cosas que se asemejen al menos a tres figuras geométricas?

3. Recread una escena que podría haber ocurrido cerca de este castaño, el cual se llama Castaño del Cristo porque durante la Guerra Civil escondieron dentro del él a un Cristo para que no fuera destruido.

4. ¿Cuántas personas hacen falta para rodear el diámetro del castaño?

5. ¿Podéis encontrar dos lugares donde el ser humano ha dejado huella negativa para la naturaleza?

6. ¿Podéis encontrar dos lugares donde el ser humano ha dejado huella positiva para la naturaleza?

7. De la gran variedad de plantas que veis, ¿'lograréis fotografiaros con dos tipos de plantas de hoja caduca y dos perennes?

8. ¿Veis alguna planta que se reproduzca por esporas? Mostradla en las fotos.

9. ¿Podríais mostrar en fotos las dos sierras que vemos desde este mirador?

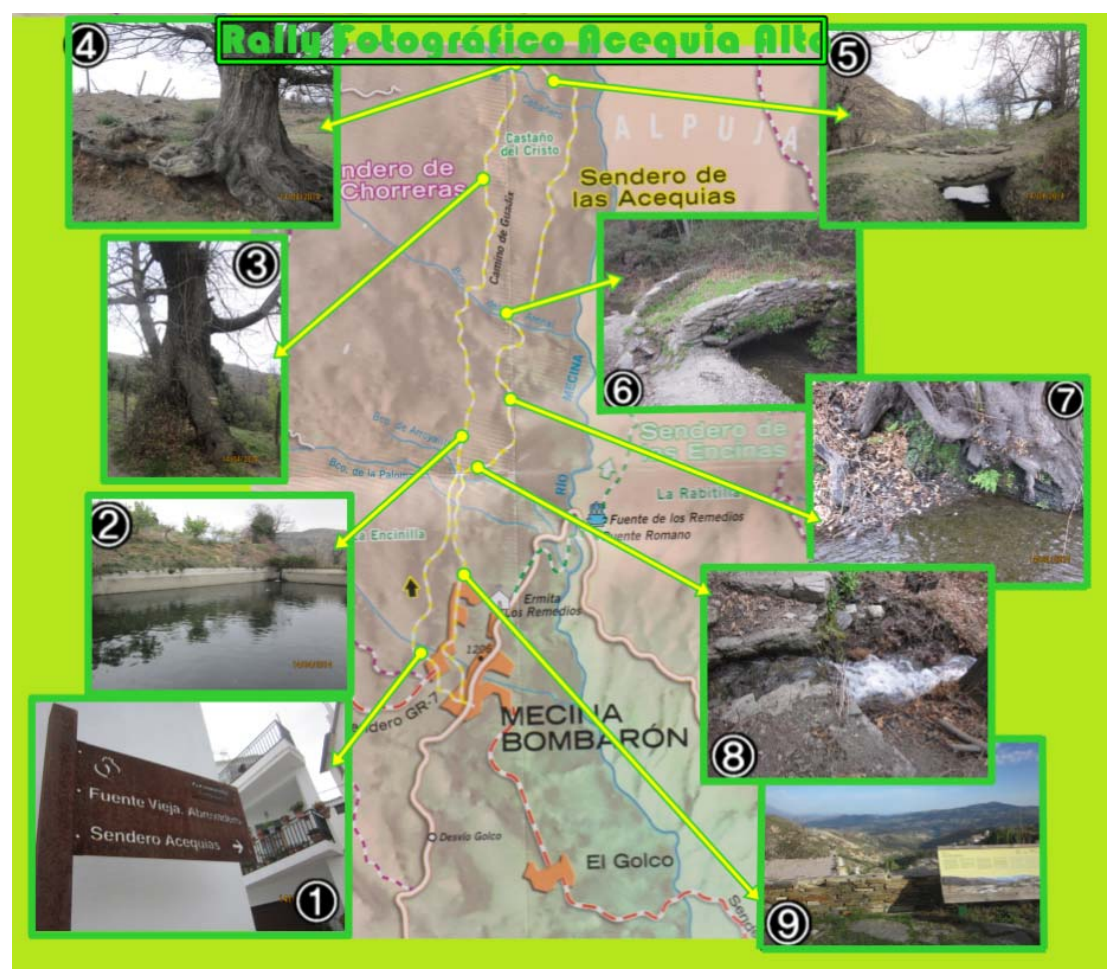

Figura 3. Mapa que llevan los participantes.

\section{4.- REFERENCIAS}

Álvarez Muñoz, A.; Carreto Díaz, M T.; Moreno Llorca, R. y Rubio Azor, F J. (2008). Senderos locales de la Alpujarra. Ediciones Alsur, S.C.A. Mancomunidad de Municipios de la Alpujarra Granadina. Plan de Desarrollo Turístico.

Caballero Blanco, P. (2009) Rallye Fotográfico. Apuntes de la asignatura Actividad Física en el Medio Natural. Disponible en http://www.slideshare.net/pelukero7/como-realizar-un-rallye-fotografico. [Consulta realizada 2014, 04 de marzo]. 
Contreras Gómez A.; Contreras Ruiz, J. y Román Lorente, C. (2005). Las actividades en el medio natural. Una propuesta interdisciplinar para educación primaria. Primera parte. Revista efdeportes, 85. Disponible en: http://www.efdeportes.com/efd85/medion.htm. [Consulta realizada 2014, 04 de marzo].

Contreras Gómez A.; Contreras Ruiz, J. y Román Lorente, C. (2005). Las actividades en el medio natural. Una propuesta interdisciplinar para educación primaria. Segunda parte. Revista efdeportes, 89. Disponible en: http://www.efdeportes.com/efd89/natural.htm. [Consulta realizada 2014, 07 de marzo].

López de Haro F. y Segura Serrano J A. (2013). Los itinerarios didácticos: un recurso interdisciplinar y vertebrador del curriculum. Espiral. Cuadernos del Profesorado, 6(12), 15-31. Disponible en: http://www.cepcuevasolula.es/espiral/articulos/ESPIRAL_VOL_6_N_12_ART_2.pdf. [Consulta realizada 2014, 04 de marzo].

Pedraza Serrano J R. (2009). El paisaje como recurso competencial y centro de interés didáctico. El Concurso Fotográfico. Revista E-co. Disponible en: http://revistaeco.cepcordoba.org/index.php?option=com_content\&view=article\&id=41:el-paisaje-comorecurso-competencial-y-centro-de-interes-didactico-el-concursofotografico\&catid=1:articulos\&Itemid=5. [Consulta realizada 2014, 05 de marzo].

Real Decreto 1631/2006, de 29 de diciembre, por el que se establecen las enseñanzas mínimas correspondientes a la Educación Secundaria Obligatoria.

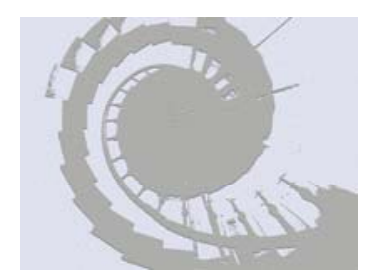

